\title{
Considering the Functioning of an e-learning System, Based on a Model for Assessing the Performance and Reliability of the System
}

\author{
Evgeny Fedkin, Saule Kumargazhanova, Saule Smailova, \\ Natalya Denissova \\ D. Serikbayev East Kazakhstan Technical University \\ Faculty of Information Technology and Intelligent Systems \\ A. K. Protazanov Str. 69, 070004 Ust-Kamenogorsk, Kazakhstan \\ e-mail: \{EFedkin, Saule.Kumargazhanova, SSmailova, NDenissova\}@ektu.kz
}

\section{György Györök}

Óbuda University, Alba Regia Technical Faculty Budai út 45, H-8000

Székesfehérvár, Hungary, e-mail: gyorok.gyorgy@amk.uni-obuda.hu

Abstract: This work discusses the LMS (Learning Management System), as part of the University's Educational Portal and identifies the main hardware/software components of such an e-learning system. The conceptual model is presented, in the form of a queuing network. Analysis of the performance and reliability of the system, is used, as criteria. The Authors assessed the productivity of the EKTU e-learning system, based on the proposed model.

Keywords: learning management system; information and communication technologies; onLine education; distance learning; educational environment; educational portal

\section{Introduction}

In a pandemic context, a global unplanned and one-time transition to distance learning technologies has become a necessity. The problems of heterogeneity of information systems, the lack of universal solutions and intersystem interaction, including learning management systems (LMS), have become aggravated.

A variety of LMS have been developed in recent years. These platforms often provide similar functionality, so choosing a learning platform is not an easy task. 
There are many methodologies for assessing the quality of e-learning in the scientific literature. In works [1-4], are given the approaches to software development based on user preferences and experience, the "user-centered" design. In the last few years, systems with adaptive learning management have appeared. This is a new type of e-learning system based on automatic recognition and prediction of user preferences and self-adaptation to user requirements. In works [57], studies are presented based on social networks and communication between learners (students) and educators (teachers).

There are also studies [8] in the field of e-learning systems devoted to the pedagogical and economic aspects of systems, such as the formation of a knowledge system, the formation of a system of professional skills and abilities, the profitability of the educational process.

E-learning systems are being developed both as separate systems and as a part of educational process management information systems in educational institutions. Many universities implement systems that integrate different systems and subsystems. Since the main activity for the university is educational activity, the educational portal acts as such a unified system. Portals form a single entry point for various categories of users, including access to the e-learning system.

\section{Designing of an e-learning System (LMS)}

Modern LMSs are designed based on web technologies. The consumer properties of systems built on the basis of web technologies are determined by such characteristics as [4]: content, design, performance level, functionality, productivity, security level.

For system users, the main characteristics are performance (system response time to user requests) and system reliability (no failures when working with the system).

The performance and reliability of the system depend on the quantitative and qualitative characteristics of the server equipment of the information system:

- Number and speed of processors (CPU)

- Amount of RAM

- Bandwidth and the amount of disk space

- Bandwidth of network equipment

The most common performance metrics for web-based systems include:

- Response time when transferring data

- Response time of the system's website

- Bandwidth (requests or bits per unit of time) 
- Number of errors per unit of time

- Number of visitors per unit of time

When considering the LMS as a system, [4] is recommended to classify certain service components rather than the services themselves. In general, the system consists of a set of databases, information processing facilities, information provision facilities and system interaction at the network level.

For a more convenient consideration of the components of the system, they can be divided into two large groups [4]:

- Application-level components that provide work with system data, implementing logical integrity and visual presentation;

- Base-level components that provide basic functions for application-level components: data transmission over the network, data security, data storage systems, etc.

In general, the e-learning system model can be represented as follows [8]:

$\{\mathrm{S}, \mathrm{SW}, \mathrm{HW}, \mathrm{A}, \mathrm{C}, \mathrm{PN}\}(1)$

Where, S - system web service infrastructure, SW - system software, HW - system hardware, A - system applications, C - system content, PN - communication networks.

Conceptually, the e-learning system model can be represented as a queuing network. To design the LMS architecture, the model needs to display a finite number of web servers, application servers, and database servers (Figure 1).

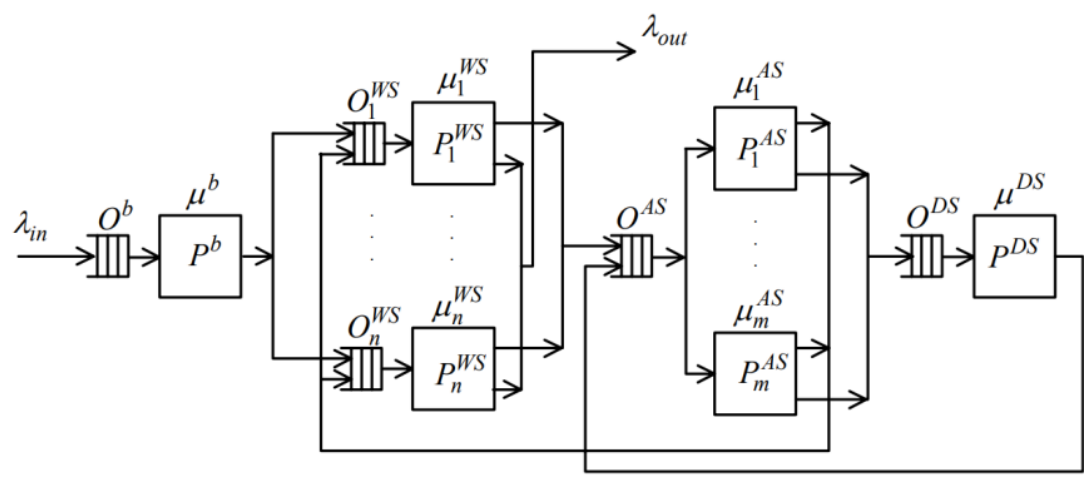

Figure 1

LMS conceptual model

The LMS work according to the given model is as follows:

- Input requests to the system arrive with intensity $\lambda_{i n}$ into the $O^{b}$ queue of the network switch $P^{b}$, which dispatches the request. 
The switch matches the virtual IP address with a valid web server address in a random time $t_{p}$ with an intensity of $\mu^{b}=\frac{1}{t_{b}}$.

- The web server $P_{i}^{W S}, i=1, n$ receives the request and generates an HTML page that is transmitted to the output stream - $\lambda_{\text {out }}$ or sends a request to the application server $P_{i}^{A S}, i=1, m$.

- The application server implements the business logic of the system and makes requests to the database server. The application server spends time $t_{j}^{A S}, j=1, m$ with the intensity $\mu_{j}^{A S}, j=1, m$, to execute the request. The functionality of this system component supports the system logic and is implemented in the form of CGI scripts or server applications. The result of the application server is the result of processing the request, which is sent to the web-server or a request to the database on the $P^{D S}$ database server.

- The database server provides a system for storing system data and provides mechanisms for receiving data and updating them through a query language (SQL, stored procedures, etc.) based on transactions. A transaction to a database management system is implemented in a random time $t^{D S}$ with an intensity $\mu^{D S}=\frac{1}{t^{D S}}$. The results of database queries are sent to the application server for further processing.

\subsection{Assessment of System Productivity Based on the Model}

Various indicators can be used to assess an e-learning system's productivity based on a web solution, which includes the average request processing time, average request size in bytes, average response size in bytes, rendering time of an HTML page in a browser, and others.

Since the central element of the e-learning system based on a web solution is the server part (web servers, application servers and database servers), the system productivity can be considered as the productivity of this particular central part of the system as a whole.

The following main indicators can be distinguished to assess the productivity of the system [9]:

- Intensity of requests (2), which characterizes the average number of requests that are simultaneously processed in the system. This indicator is determined by the number of users of the system and the number of requests that the user generates on average when working with the system. 


$$
\rho=\lambda \cdot t_{r s t}
$$

where $\lambda$ is the intensity of the flow of requests; $t_{r s t}$ - request service time

- Probability of rejection (3) - the proportion of requests that are rejected. This indicator for a quality system should tend to zero. Modern systems based on web solutions have dozens and even hundreds of thousands of service channels, which means that the probability of failure for such systems is practically zero.

$$
\rho_{r j c}=\frac{\rho^{n}}{n !} \cdot \rho_{o}
$$

where $\mathrm{n}$ is the number of service channels, $\rho$ is the intensity of requests, $\rho_{o}=\frac{1}{\sum_{k=0}^{n} \frac{\rho^{k}}{k !}}$ is the probability that the channel is free.

Nominal performance of the system (4) - the number of requests that the system can process per unit of time.

$$
N=\frac{n}{\rho}
$$

where $\mathrm{n}$ is the number of service channels, $\rho$ is the intensity of requests.

The actual system performance (5) is \% of system utilization of the nominal system performance:

$$
F=\frac{\lambda}{N}
$$

where $\lambda$ is the intensity of the flow of requests, $\mathrm{N}$ is the nominal performance of the system.

The required size of the data transmission channel (6) shows the required speed of the data transmission channel through the network required for the system to work in the network.

$$
S=\frac{\lambda \cdot r}{125 \cdot 60} M b p s
$$

Where, $\lambda$ is the intensity of the flow of requests, $r$ is the average size of a response to a request in kilobytes, 125 kilobytes per $1 \mathrm{Mbps}, 60$ seconds per minute.

The presented model is the basis for developing e-learning systems and assessing their performance. 


\section{Implementation of an e-learning System Based on EKTU}

As mentioned above, the main business processes at universities are those related to learning. To automate these processes, universities use heterogeneous systems that provide one or another aspect of work in this area. Portal solutions are used to ensure the connectivity of these heterogeneous systems in higher educational institutions.

In EKTU named after D. Serikbayev, since 2003, a similar solution has been developed $[10,11]$. The educational portal is the central part of the university information system, which is shown in Figure 2.

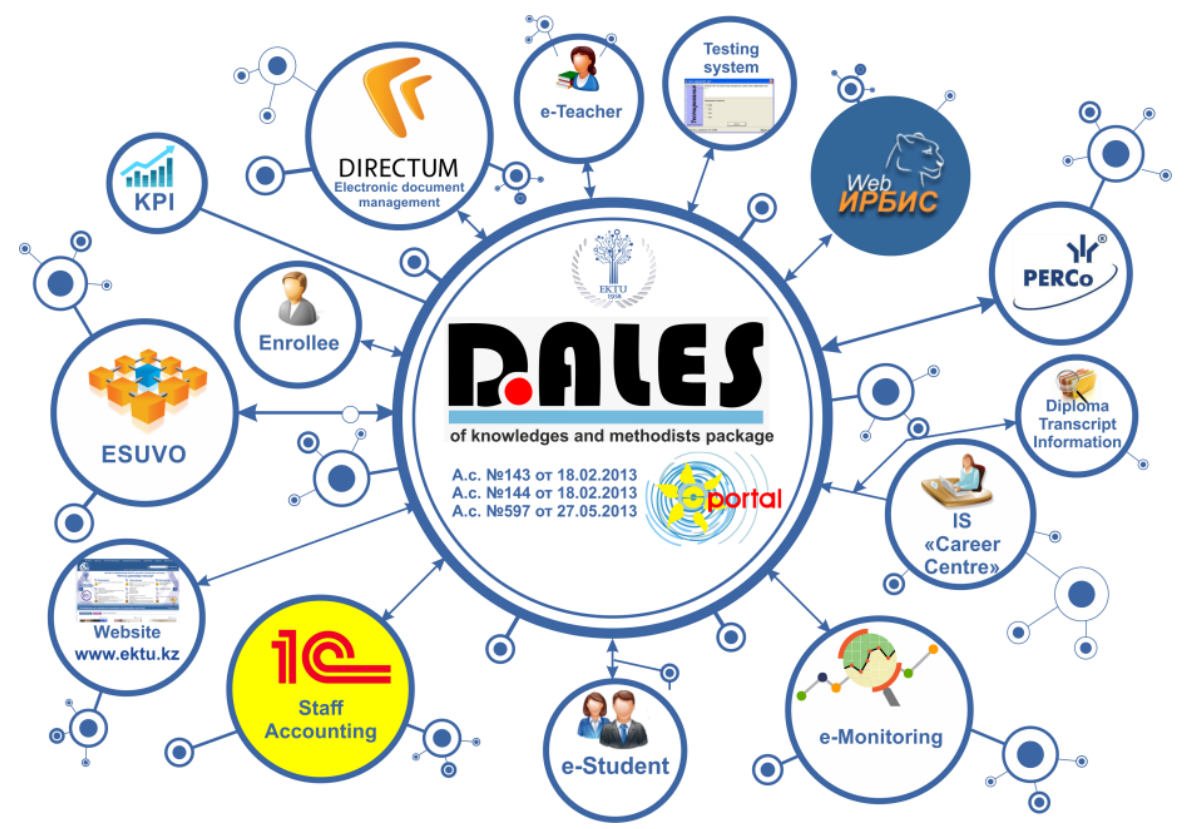

Figure 2

Scheme of the information system of EKTU

As can be seen from the scheme, the EKTU educational portal, being the central part of the information system, interacts with other information systems of the university - the IRBIS library system, access control system, accounting (1C), electronic document management system (Directum), the official website of the University and other systems. 


\subsection{Educational Portal of EKTU Named after D. Serikbayev}

The architecture of the EKTU educational portal is built using client-server technology and is shown in Figure 3. The database management system Microsoft SQL Server 2017 is used to store data. Information is accessed using the website (http://www.do.ektu.kz) running under the control of a web server, the Internet Information Server 10.0, based on the Windows 2019 Server operating system.

The use of a thin client architecture, in which all components are located on the server, allows minimizing traffic, both from the client-side and from the server-side.

This scheme allows you to separate the command-control functions and the functions of providing and forming outputs. Due to the flexibility of the proposed scheme, you can make changes to one component without correction or with minimal correction of the other. In addition, the synthesis of the educational process control system is simplified since each block can be designed relatively independently, observing only the specifications of the interface between the blocks.

1. Internet clients

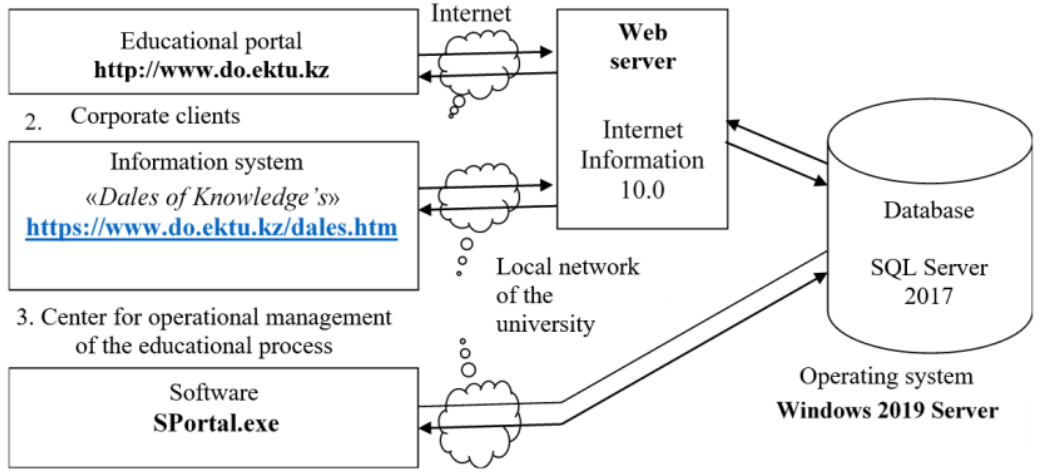

Figure 3

Educational portal architecture

Using the web interface to access the educational portal of the university provides many advantages in the form of versatility, the ability to work remotely, and interactivity.

Figure 4 shows the hardware and software structure of the EKTU Educational portal. 


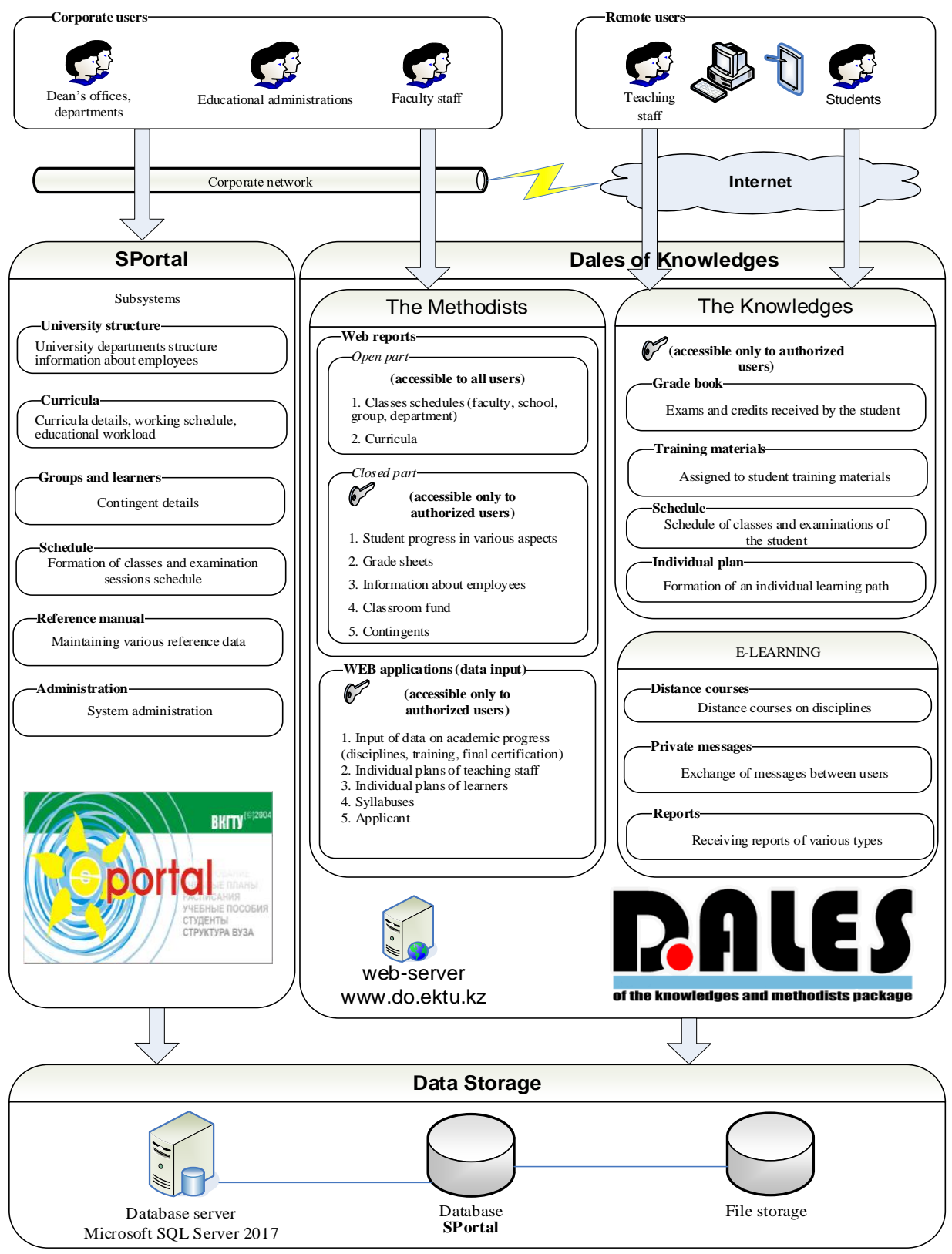

Figure 4

The structure of the EKTU portal 
This structure includes the following components:

1. Database management system. This component is intended to ensure the functioning of a relational database for an educational portal. In our case, Microsoft SQL Server 2017 acts as a database management server. The main databases on which the university educational portal operates are

a) SPortal is a central database that stores data related to the provision of the educational process (contingent, curricula, disciplines, teaching staff, etc.)

b) File storage - a database designed to store binary data.

2. SPortal software package (fig. 4). This software package is a stand-alone windows-application for working with the database of the educational portal in the corporate environment of the university. SPortal is intended for the administrative services of the university - dean's offices, departments, educational management to maintain the data required for the organization of the educational process and various reference data. This software package includes such subsystems as:

A) The structure of the university - designed to store the organizational structure of the university and the staff. This system is closely integrated with the "1C: Personnel" system from which information about the structural divisions of the university and their personnel is received.

B) Curricula - designed to store information about various curricula on which training is carried out at the university, the formation and distribution of academic streams and teaching staff workload.

C) Groups and students - designed to keep records of the university contingent

D) Schedule - designed for scheduling classes and exams

E) Reference books - designed to maintain various reference books that are required for the operation of various subsystems of the educational portal.

F) Administration - designed to configure various subsystems of the educational portal.

This software package was developed using the Embarcadero Delphi 2009 programming environment. This environment has advanced tools for working with databases and a wide range of tools for displaying and editing data.

Interaction with the Microsoft SQL Server 2017 database server is based on ActiveX Data Object (ADO) technology using the Microsoft OLEDB Provider for SQL Server. The scheme of work of the application with this database is shown in Figure 5. 


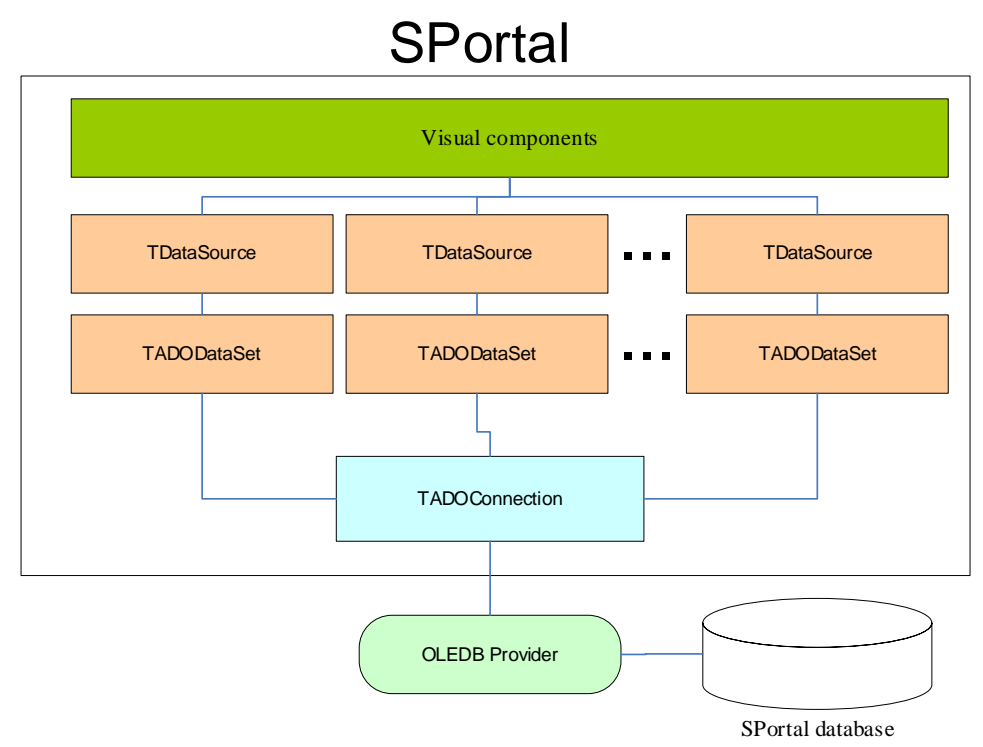

Figure 5

Scheme of work of SPortal software with a database

As you can see from the scheme shown in Figure 5, the TADOConnection component is used to connect to the database, which implements the connection to the database through the OLEDB provider. This component interacts with the TADODataSet components, which is a set of data in a database. The TDataSource components are used to interact with the data set in the TADODataSet and visual components. This component is responsible for retrieving data from the data source, passing it to the visual component for display and transferring updated data back to the dataset.

3. Dales: The Knowledges Web Services. These services are a set of web applications that provide an access point to various functionalities of the educational portal. These services are divided into the following categories:

A) The Methodist - web services are designed for teaching staff and administrative staff to work with the educational portal. This part is divided into:

- An open part that is accessible to all users without authorization. This part includes reports on class schedule and curriculum

- A closed part, which is accessible only to authorized employees of the university. This part includes reports on progress, contingents, classroom fund, etc.

- Web applications that are designed to enter data into the database of the educational portal by various employees of the university. This part includes journals of progress and attendance, grade sheets, data on applicants, individual plans of teaching staff and students, etc. 
B) The knowledge - is a student's personal account, where he can get information about his progress, schedule, training plan, etc.

C) E-learning - is an e-learning system (LMS), which provides training on various courses for teaching staff and students.

Web services operate on a "request-response" basis (Figure 6).

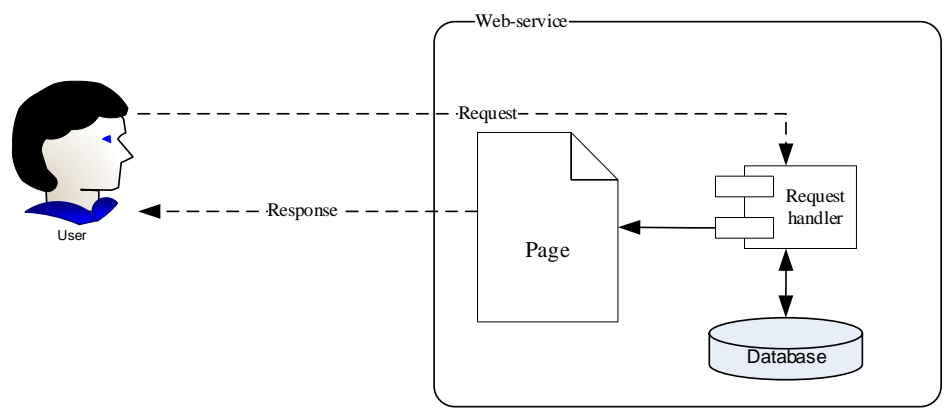

Figure 6

Scheme of the Web service operation

These web services are operated by the Microsoft Internet Information Services 10.0 web server. As technologies for implementation, technologies such as ASP (for the implementation of reports and data entry systems) and ASP.Net (for complex web applications, such as an e-learning system) are used.

Let us consider how the operation of the reporting system and the data entry system of web services based on ASP technology is implemented, which are implemented on the educational portal of EKTU. The implemented scheme of work based on this technology is shown in Figure 7.
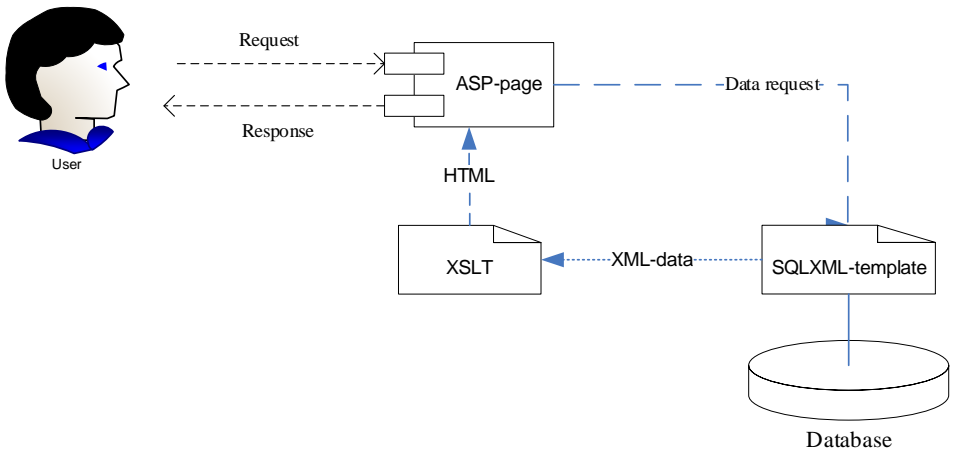

Figure 7

Scheme of the ASP-page of the educational portal operation

4. Directory services. This architecture component is intended for storing data about users, computers, user groups, group membership, and authentication 
and authorization of system users. In our case, the directory service is the Microsoft Active Directory. This service provides data based on the ektu.kz domain.

\subsection{E-learning System (LMS) as Part of the EKTU Educational Portal}

The EKTU e-learning system is implemented on a single basis of the educational portal. From this portal, the system receives information about the contingent of students, information about active groups, data about existing teachers, data on disciplines, information on individual plans of students, data on current curricula. Based on the received data in the system:

- Thee e-courses are formed in groups, assigned to teachers, by semesters

- Various types of reports are created

- Export of progress to the educational portal is performed

Let us consider the software architecture of the server part of the distance learning system since it is it that determines the main functionality of the system. The software structure of the server part of the distance learning system is shown in Figure 8.

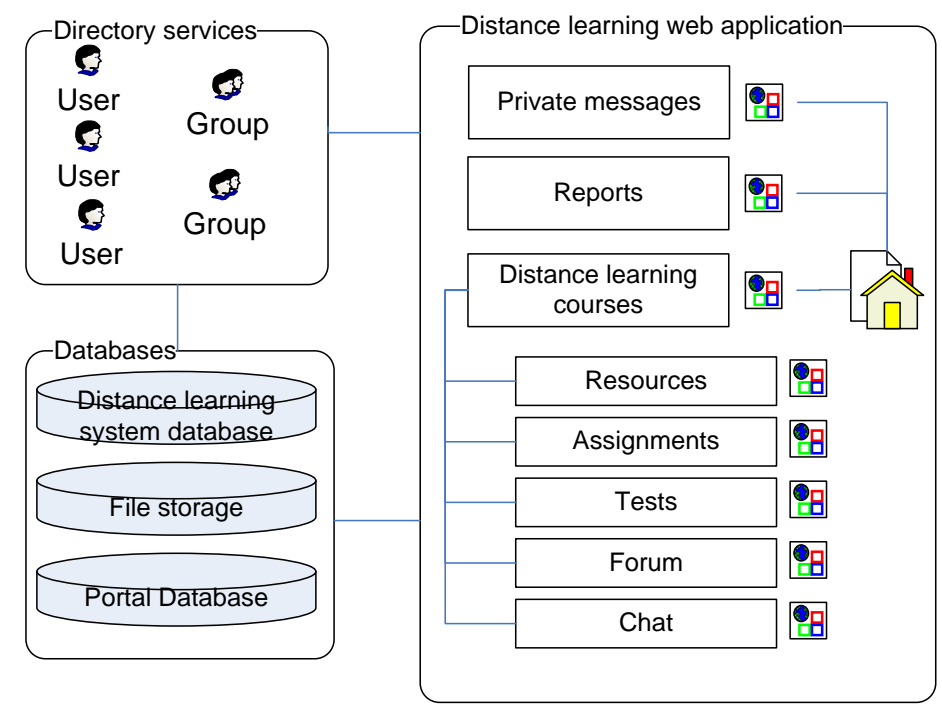

Figure 8

LMS software architecture

Consider the elements of the system software architecture presented in Figure 8. 
- Directory services. This part is a repository of data about users, security groups and users' membership in them. This element of the architecture provides authentication and authorization of users of the educational portal and the distance learning system as part of the educational portal. Other elements of the system have access to this element, which makes it possible to provide a single point of safety.

- Database. In this part, we have three databases that support the functioning of the distance learning system. The databases operate on the basis of the Microsoft SQL Server 2017 database management system. The system has the following databases:

a) Database of the educational portal. This database contains information from the educational portal of the university and contains such information as a catalog of disciplines, a catalog of curricula, student contingent, information about the teaching staff and other data.

b) File storage. This database contains binary data representing files of various formats (Word, Excel, PDF, etc.). The file store is displayed in a separate store so as not to mix binary and relational data in the system.

c) Database of the distance learning system. This database contains data that is intended for the functioning of distance learning. This database is linked to the database of the educational portal, which makes it possible not to duplicate data between the database of the educational portal and the database of distance learning.

- Web-based e-learning application. This part is a web application that provides the formation of dynamic HTML-pages based on asp.net 4.0 technology for displaying to users. In this part, we can distinguish the following groups of dynamic pages:

a) Home page - this page is the entrance page of the distance learning system. This page displays ads posted in the system for various groups of users and contains transitions to other elements.

b) Module "Private messages" - this module is designed to exchange messages between users. Messages in this module are in the mode of dialogue between users according to the 1: 1 scheme.

c) "Reports" module - this module is a set of dynamic reports on the functioning of the distance learning system: data on courses, user activity, progress (успеваемость), unchecked assignments and other types of reports.

d) Module "Distant Learning Courses" - this module is the main part of the distance learning system that provides the page operation of individual distance courses. This module contains the following submodules: resources, assignments, tests, chat. 


\subsection{Assessment of the Effectiveness of the EKTU e-learning System}

Various indicators can be used to assess the efficiency and reliability of systems. For our model of an e-learning system based on a web solution, the main indicators for assessing the efficiency and reliability of the system are related to the number of users who work in the system at some point in time and the network traffic that is generated during operation. Consequently, we will assess the effectiveness of the VKTU e-learning system based on these indicators.

The EKTU e-learning system has the following hardware:

1) Web server: HPE ProLiant DL325 Gen10, AMD EPYC 7351P 16-Core Processor, $2.4 \mathrm{GHz}, 96 \mathrm{~Gb}$ RAM, $6 * 1.5 \mathrm{~Tb}$ HDD, RAID 1

2) Database Server HPE ProLiant DL385 Gen10, 2 * AMD EPYC 7251 8-Core Processor, $2.1 \mathrm{GHz}, 64 \mathrm{~Gb}$ RAM, $8 * 1$ Tb HDD, RAID 1

3) Corporate network - $100 \mathrm{Mb}$

4) Network inside the server room - $1 \mathrm{~Gb}$

5) Internet connections - $500 \mathrm{Mb}$

This hardware configuration allows serving a significant number of system users. The graphs (Fig. 10,11) show the activity of users in the e-learning system (students and teaching staff).

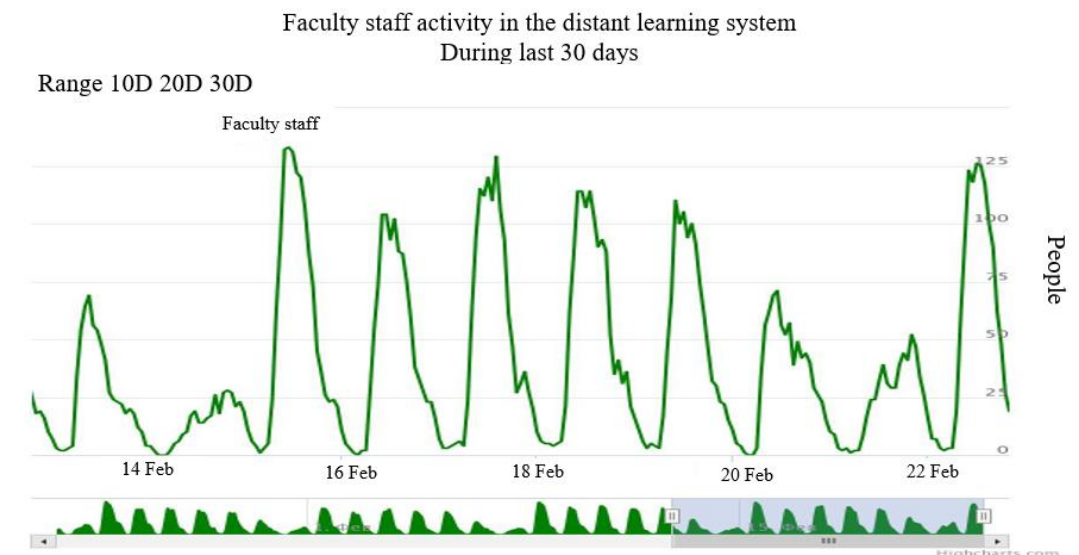

Figure 10

Faculty staff activity in the system 


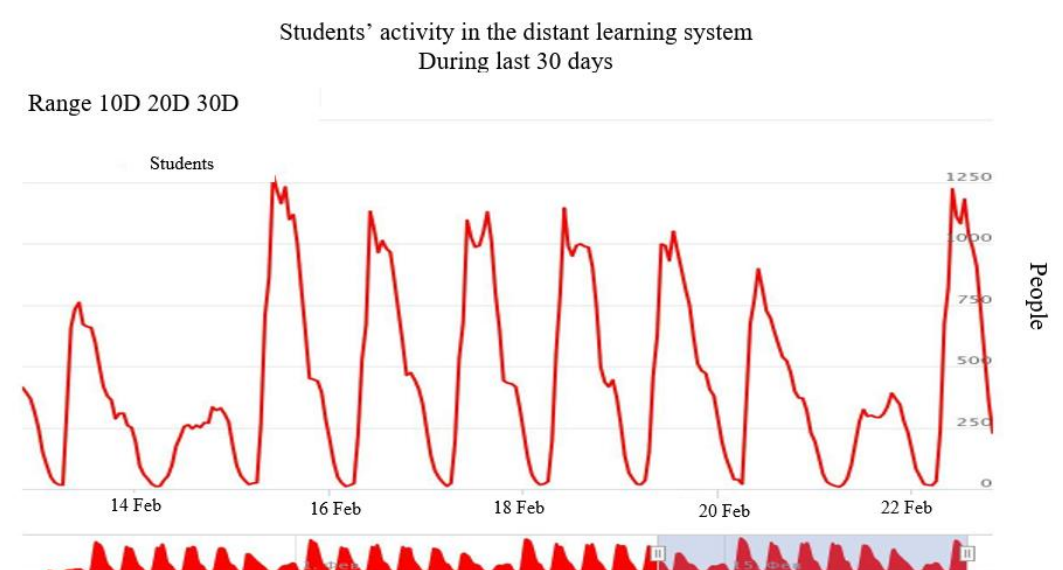

Figure 11

Students' activity in the system

As you can see from the graphs of activity, up to 1500 users are simultaneously daily in the system.

To assess the performance of the server part of the system, we will analyze the operation of the system's web server. To do this, we will use the log of the Microsoft Internet Information Services 10.0 web server for the period from December 1 to December 31, 2020. Summary data on the analysis of the log are given in Table 1. This table contains the following information:

- Request handler - is a server-side script that processes the user's request

- Total requests - the total number of requests to this handler for the period under review.

- Bytes / request received - the average value of received bytes per 1 request

- Bytes / Request Sent - the average value of sent bytes per 1 request

Average execution time (ms) - the average execution time of 1 request in milliseconds

As you can see from the table, most queries are executed within $500 \mathrm{~ms}$, which indicates the performance of the system since it is considered that if the user's query lasts less than 1 second, then he believes that the system is working without delays.

We can also see that there are requests that take more than 1 second to complete. These requests are related to uploading files or downloading files. The speed of these requests directly depends on the volume of transmitted data and, accordingly, increases with a large amount of data. Users are aware of this file and do not perceive this phenomenon as a lack of system response. 
Table 1

System web server log analysis data

\begin{tabular}{|c|c|c|c|c|}
\hline Request handler & $\begin{array}{l}\text { Total } \\
\text { requests }\end{array}$ & $\begin{array}{l}\text { Byte I } \\
\text { request } \\
\text { received }\end{array}$ & $\begin{array}{l}\text { Byte / } \\
\text { request } \\
\text { sent }\end{array}$ & $\begin{array}{l}\text { Average } \\
\text { execution } \\
\text { time }(\mathrm{ms})\end{array}$ \\
\hline $\begin{array}{ll}\text { /SDO/Chat/Handler } & \text { (Chat } \\
\text { operation) } & \\
\end{array}$ & 34921729 & 2805 & 477 & 294 \\
\hline /SDO/Service (user search) & 4383143 & 25395 & 810 & 360 \\
\hline $\begin{array}{l}\text { /SDO/Course/Details.aspx } \\
\text { (course page) }\end{array}$ & 1031793 & 2826 & 14062 & 679 \\
\hline $\begin{array}{l}\text { ISDO/Test/ImageTest.aspx } \\
\text { (picture from the base for the } \\
\text { test) }\end{array}$ & 761530 & 2412 & 7588 & 458 \\
\hline $\begin{array}{l}\text { /SDO/Chat/Default.aspx } \\
\text { (Course chat page) }\end{array}$ & 500220 & 2215 & 6662 & 402 \\
\hline $\begin{array}{ll}\text { /SDO/Default.aspx } & \text { (List of } \\
\text { courses for the user) } & \end{array}$ & 440763 & 2098 & 5673 & 1107 \\
\hline /SDO/Entry.aspx (Home page) & 398081 & 1743 & 21641 & 604 \\
\hline $\begin{array}{l}\text { /SDO/Course/Score.aspx } \\
\text { (Course performance) }\end{array}$ & 220684 & 2320 & 9432 & 395 \\
\hline $\begin{array}{l}\text { /SDO/Messages.aspx (Private } \\
\text { messages) }\end{array}$ & 207699 & 3842 & 8445 & 567 \\
\hline $\begin{array}{l}\text { /SDO/Service/Work-study } \\
\text { (Submitting / uploading } \\
\text { completed work on the course) }\end{array}$ & 139504 & 2338 & 1001810 & 4058 \\
\hline $\begin{array}{l}\text { /SDO/Service/Work (uploading } \\
\text { a file with an assignment) }\end{array}$ & 118592 & 2124 & 474271 & 4166 \\
\hline $\begin{array}{l}\text { /SDO/Course/Work.aspx } \\
\text { (assessment of completed } \\
\text { assignments) }\end{array}$ & 112530 & 18094 & 18661 & 541 \\
\hline $\begin{array}{l}\text { /SDO/Service/Resource } \\
\text { (loading course resource) }\end{array}$ & 105809 & 2184 & 652169 & 3678 \\
\hline $\begin{array}{l}\text { /SDO/Test/Detail.aspx } \quad \text { (view } \\
\text { loaded test) }\end{array}$ & 65531 & 2001 & 3780 & 272 \\
\hline /SDO/Test/TestForm.aspx (test) & 48088 & 2854 & 5342 & 814 \\
\hline $\begin{array}{l}\text { ISDO/Course/AddWork.aspx } \\
\text { (adding an assignment to a } \\
\text { course) }\end{array}$ & 36834 & 7526 & 8562 & 337 \\
\hline $\begin{array}{l}\text { /SDO/Course/ActiveWorks.asp } \\
\mathrm{x} \quad \text { (list of unchecked } \\
\text { assignments) }\end{array}$ & 28709 & 3316 & 12812 & 1389 \\
\hline $\begin{array}{l}\text { ISDO/Service/PrivMessFile } \\
\text { (private messages file) }\end{array}$ & 19905 & 2525 & 1232567 & 3878 \\
\hline $\begin{array}{l}\text { /SDO/Course/Group.aspx } \\
\text { (group list of the course) }\end{array}$ & 17417 & 2491 & 8847 & 465 \\
\hline
\end{tabular}




\begin{tabular}{|l|l|l|l|l|}
\hline $\begin{array}{l}\text { /SDO/Test/LoadTest.aspx } \\
\text { (loading test for course) }\end{array}$ & 13958 & 7050 & 13739 & 396 \\
\hline $\begin{array}{l}\text { /SDO/Course/AddResource.asp } \\
\text { x (adding a resource to a course) }\end{array}$ & 11117 & 5796 & 5641 & 326 \\
\hline $\begin{array}{l}\text { /SDO/Course/GraphComm.asp } \\
\text { x (schedule of assignments for } \\
\text { the course) }\end{array}$ & 10322 & 2451 & 8166 & 334 \\
\hline /SDO/Group.aspx (group list) & 9372 & 2413 & 6377 & 417 \\
\hline $\begin{array}{l}\text { /SDO/Forum/Default.aspx } \\
\text { (course forum) }\end{array}$ & 7220 & 1963 & 6650 & 408 \\
\hline $\begin{array}{l}\text { /SDO/Test/Appelation.aspx } \\
\text { (test appellation) }\end{array}$ & 6550 & 4746 & 6189 & 372 \\
\hline $\begin{array}{l}\text { /SDO/Forum/Topic.aspx } \\
\text { (course form topic) }\end{array}$ & 4497 & 4022 & 9374 & 496 \\
\hline $\begin{array}{l}\text { /SDO/Instruction.aspx (system } \\
\text { instructions) }\end{array}$ & 4021 & 2148 & 4036 & 824 \\
\hline $\begin{array}{l}\text { /SDO/Test/TestResult.aspx } \\
\text { (test result) }\end{array}$ & 3691 & 3276 & 8667 & 621 \\
\hline $\begin{array}{l}\text { /SDO/Course/Log.aspx } \\
\text { (activity log) }\end{array}$ & 3010 & 13823 & 8506 & 501 \\
\hline $\begin{array}{l}\text { /SDO/Test/ViewTest.aspx } \\
\text { (view the completed test) }\end{array}$ & 1813 & 2882 & 19127 & 362 \\
\hline
\end{tabular}

Based on the system operation's data, we will assess the system performance based on the indicators from paragraph 1.1.

Based on the given data, it has the following initial values:

- Intensity of requests to the system $\lambda=978$ requests / minute

- Average time to service a request t_rst $=361 \mathrm{~ms}=0.006$ minutes

- Number of service channels $n=10,000$ (the e-learning system web application is configured for this number of simultaneous processing)

- Average size of a response to a request in kilobytes - 7.89 Kbytes

Then we calculate the performance indicators of the system:

- Intensity of requests $\rho=\lambda *$ t_rst $=978 * 0.006=5.87$, i.e. on average, the system simultaneously processes about 6 requests.

- Probability of failure - as described in Section 1.1, with a large value of the number of service channels and intensity, the probability of failure actually becomes equal to 0 .

- Nominal performance of the system $\mathrm{N}=\mathrm{n} / \rho=10000 / 5.87=1704.2$, i.e. on average, the system can process about 1,700 applications per minute.

- Actual performance of the system $\mathrm{F}=\lambda / \mathrm{N}=978 / 1704.2=0.574$, i.e. on average, the system is loaded by $57 \%$. 
- The required size of the data transmission channel:

$$
\mathrm{S}=(\lambda * \mathrm{r}) /(125 * 60)=(978 * 7.89) /(125 * 60)=1.03 \mathrm{Mbps}
$$

The graph (Fig. 12) shows the load on the network component of the web server, which shows the average input and output bytes per second.

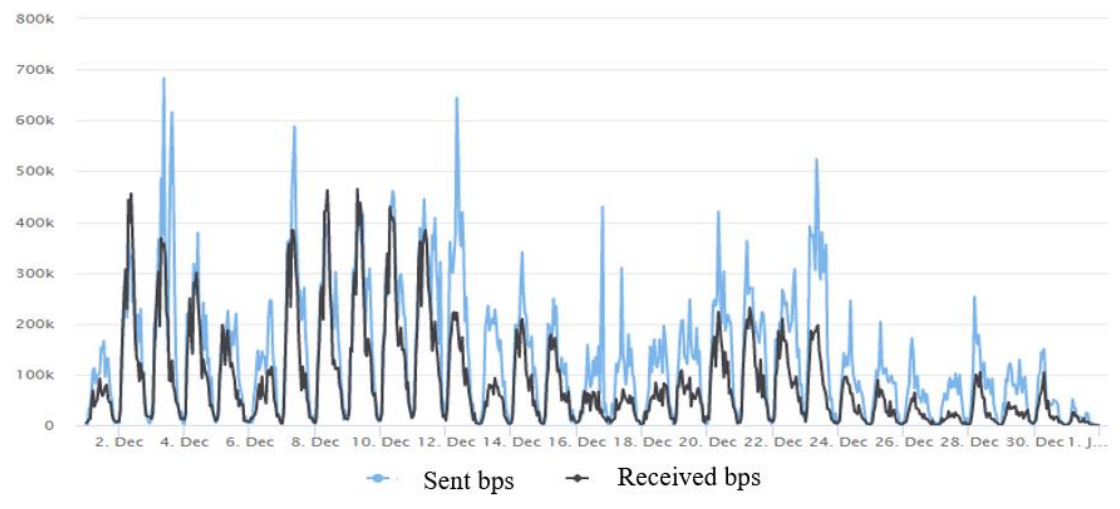

Figure 12

Load on the network component of the web server

As you can see from the presented graph, the traffic generated by the web server can easily be served by the network interfaces on the available resources.

\section{Conclusions}

Currently, there are many e-learning systems that universities use in the educational process. Such systems are often included in portal solutions (educational portals) that are available in universities and provide a single-entry point for different categories of users.

In this study, the main hardware and software components of the e-learning system were identified as part of the University's Educational Portal.

The model for assessing the functioning of the e-learning system presented in the article used the QS criteria: performance analysis (system response time to user requests) and system reliability (no failures when working with the system).

VKTU named after D. Serikbayev has its own portal solution (www.do.ektu.kz), with an e-learning system that allows implementation of e-learning, combining all participants in the educational process and is an integral part of the unified educational environment of the University. The implementation of the e-learning system within a single portal solution, made it possible to achieve the high speed of the e-learning system, by reducing the overhead costs associated with the coordination of the work of heterogeneous systems for managing the educational process at the University. The system allowed for improvements, the quality of work and interaction of various users in the system and, as the analysis of the work of this system showed, it is quite effective. 


\section{Acknowledgment}

This work was supported by the Ministry of Education and Science of the Republic of Kazakhstan under the grant financing program for the 2020-2022 years by the program 08856846 "Methodology for creating a liberal model of On-Line education for higher education institutions of the Republic of Kazakhstan".

\section{References}

[1] T. Y. Wang, C. H. Wang, «E-Learning Platform of STEAM Aesthetic Course Materials Based on User Experience» In Proc. of the $1^{\text {st }}$ International Cognitive Cities Conference (IC3), IEEE, August 2018, pp. 123-128

[2] P. Zaharias, C. Pappas. Quality management of learning management systems: A user experience perspective, in Current Issues in Emerging eLearning, Vol. 3(1), 2016, p. 5

[3] R. Kraleva. Designing an Interface for a Mobile Application Based on Children's Opinion, in International Journal of Interactive Mobile Technologies, Vol. 11(1), 2017, pp. 53-70

[4] Legkov K. E. Models of information subsystems of automated control systems for complex objects, in T-Comm. 2017, No. 5

[5] J. W. Lin, H. C. K. Lin. User acceptance in a computer supported collaborative learning (CSCL) environment with social network awareness (SNA) support, in Australasian Journal of Educational Technology, Vol. 35(1), 2019, pp. 100-115

[6] V. Narayan, J. Herrington, and T. Cochrane. Design principles for heutagogical learning: Implementing student-determined learning with mobile and social media tools, in Australasian Journal of Educational Technology, Vol. 35(3), 2019, pp. 86-101

[7] I. Valova, M. Marinov. Facebook as a Tool Aiding University EducationWhether it is Possible and Useful, in TEM Journal, Vol. 8(2), 2019, pp. 670676

[8] Dolzhenko A. I. Modeling of a corporate information system, in Bulletin of higher educational institutions. North Caucasian region. Series: Social Sciences. 2006, No. 2

[9] Bain A. M. Mathematical model of the distance learning system, in Bulletin of higher educational institutions. Electronics, 2010, No. 2 (82), pp. 71-75

[10] Mutanov G. M., Shakarimova A. B. Educational portal of the university. Theory and practice. - Ust-Kamenogorsk: EKSTU, 2006, 352 p.

[11] Transformation of a technical university into an innovative university: methodology and practice / Ed. G. M. Mutanov. - Ust-Kamenogorsk: EKSTU, 2007, 480 p. 
[12] Dmitrenko T. A., Derkach T. N., Dmitrenko A. A. Technology of developing a distance learning system, in Economics. Informatics. 2014, No. 8-1 (179) pp. $128-137$

[13] Naumov A. V., Mkhitaryan G. A., Rybalko A. A. Software set of intellectual support and security of lms mai class. Net, in Bulletin of SUSU. Series: Mathematical Modeling and Programming. 2016. No. 4, pp. 129-140

[14] Kumargazhanova, S., Baklanov, A., Györök, Gy., et al.: Development of the Information and Analytical System in the Control of Management of University Scientific and Educational Activities, Acta Polytechnica Hungarica, Vol. 15, No. 4, 2018, pp. 27-44, DOI: 10.12700/APH.15.4.2018.4.2

[15] Baklanov, A, Baklanova, O, Grigoryeva, S, Kumargazhanova, S, Györök, G, et al.: The Development of Hybrid IP Architecture for Solving the Problems of Heating Networks, in Acta Polytechnica Hungarica, №1 (17), 2020, pp. 123-140, DOI: 10.12700/APH.17.1.2020.1.7

[16] Rybakova, D., Sygynganova, I., Kumargazhanova, S., Baklanov, A., Shvets, O.: Application of a CPU Streaming Technology to Work of the Computer with Data Coming from the Network on the Example of a Heating Station. $18^{\text {th }}$ International Conference of Young Specialists on Micro/Nanotechnologies and Electron Devices (EDM), Erlagol, Russia, 2017, pp. 128-130

[17] Kassymkhanova, D., Kurochkin, D., Denissova, N., Kumargazhanova, S., Tlebaldinova, A. Majority voting approach and fuzzy logic rules in license plate recognition process, in The $8^{\text {th }}$ International Conference on Application of Information and Communication Technologies (AICT 2014), Astana, 2014, pp. 155-159

[18] Karymsakova, I., Denissova, N., Kumargazhanova, S., Krak, I. Robotic plasma spraying system for implants of complex structure: $3 \mathrm{~d}$ model and motion planning, in International Journal of Computing, 19(2) 2020, pp. 224232. On-line ISSN 2312-5381

[19] Azarova, A., Azarova, L., Pavlov, S., Savina, N., Kaplun, I., Wójcik, W., Smailova, S., Kalizhanova, A. Information technologies for assessing the quality of it-specialties graduates' training of university by means of fuzzy logic and neural networks, in International Journal of Electronics and Telecommunications, 66(3) 2020, pp. 411-416

[20] Uvaliyeva, I., Smailova, S. Development of decision support system to control the quality of education, in Proceedings of the International Conference «Application of Information and Communication TechnologiesAICT 2014», Astana, 2014, pp. 528-532

[21] Lutsiv, N., Maksymyuk, T., Beshley, M., Lavriv, O., Vokorokos, L., Gazda, J. (2022) Deep Semisupervised Learning-Based Network Anomaly Detection in Heterogeneous Information Systems. CMC-Computers, Materials \& Continua, 70(1) 413-431 